\title{
EN EL UMBRAL DE LA HISTORIA
}

En la medida de lo posible, el historiador ha de manifestar la realidad de su historia, ha de dotarla de tal sentido, que a su luz pueda caminarse, sin estorbo, del detalle al conjunto, del hecho aislado al sujeto agente de cuya vida total es expresión aquel hecho. La historia es, ante todo, la conexión de valores en que un pueblo articula su existencia; su realidad se hace presente en la expresión temporal y geográfica de sus dimensiones valiosas.

No importa el desacuerdo sobre qué sean o cómo sean los valores, ni la consiguiente imposibilidad de hacerlos generalmente válidos. Basta que el historiador crea y tenga fe en la fe objetivada de un pueblo, en una fe justificada en manifiestas grandezas, o en el grave recelo de no poder alcanzarlas. Un pueblo, como un héroe trágico, ha de mostrarse digno de enfrentarse con su destino ineluctable, es decir, con la extinción en que, pronto o tarde, se desvanece como alto valor, y cesa de ser auténtico tema de historia. La obra pretérita seguirá existiendo siempre como un posible y durable presente; los descendientes de quienes la crearon, no. Ya no hay sumerios, ni romanos, ni griegos.

En la historia se realizan en múltiples modos las posibilidades humanas de crear algo valioso e irradiante, apto para mover a otros hombres a rebasar el nivel de la insignificancia cotidiana, para tensar la mente, la fantasía o el ánimo. Ahora bien: la historia no se hace universal mediante la supresión de las barreras que separan y singularizan a los pueblos, sino difundiendo valores universalizables. I_as frondas de los árboles históricos se tocan en sus cimas, pero los árboles mismos no se entrelazan en la profundidad sin luz de sus raíces (a menos que un pueblo sea absorbido sin resto en la vida de otro). Lo que se universaliza son ciertos valores, por ejemplo, la creencia hebrea en el Mesias, advenido ya para incontables gentes; o las formas exactas del pensar de los griegos antiguos. Se extienden muchas cosas, importantes o menudas, desde el uso de la rueda hasta ciertas clases de danza. A pesar de lo cual los pueblos creadores o receptores de unos $u$ otros valores conservan su singularidad, aparecen como unidades dentro de la totalidad de la vida humana, siempre pluralizada.

Hay, pues, que dar por supuesta la existencia de algún impor- 
tante valor antes de tratar de describir y de entender el proceso histórico de una colectividad humana. El mero hecho de existir para que la vida física prosiga subsistiendo en mejores o peores condiciones, no constituye historia. En todo caso, el caos confuso de hechos y acontecimientos fragmentados que el historiador del pasado o del presente saca a luz, no es por sí solo historia. Ni lo es tampoco el hecho de ser "peculiar" psicológicamente.

Así concebida, la tarea histórica es aventurada, dado que nunca se llegará a una certidumbre, válida para los más, como lo es la verdad de las ciencias exactas. Quienes no sientan previa simpatía por las acciones y creaciones de un pueblo, no las aceptarán como valiosas por mucho que las encarezcamos. Sin una adecuada receptividad para ciertas clases de valores, éstos pueden resbalar sobre la sensibilidad del lector; así aconteció al teatro de Shakespeare en el siglo XviII, y lo mismo ocurre hoy con grandes valores de la historia asiática, o ignorados o incomprensibles.

Por todos estos motivos, mi historia aspira a satisfacer únicamente las exigencias rigurosas que me he puesto a mí mismo. Parto de la creencia de haber realizado el pueblo hispano obras de alto valor, en enlace casi siempre con situaciones muy apretadas y desapacibles. He tenido así que construir una figura historiable en la cual cupiesen tanto las posibilidades de los desarrollos como sus opuestos. He tomado como centro y agente de esta historia el taller de vida en que la historia ha ido fraguándose, y no parciales rasgos psicológicos, siempre genéricos e inconexos. No he pensado tampoco que las circunstancias exteriores fueran aislables del curso mismo de la vida, como si ésta fuese una realidad ya previamente dada sobre la cual cayeran causas o motivos. La vida histórica consiste en un curso o proceso interior a ella misma, dentro del cual las motivaciones exteriores adquieren forma y realidad, es decir, se convierten en hechos y acontecimientos dotados de sentido.

Estos últimos dibujan la peculiar fisonomía de un pueblo, y hacen patente el "dentro" de su vida, nunca igual al de otras comu. nidades humanas. Este "dentro" no es una realidad estática y acabada, análoga a la sustancia clásica; es una realidad dinámica, análoga a una función, o a una "invariante" (en sentido matemático). Pero el término "dentro" es ambiguo: puede designar el h e cho $\mathrm{d}$ e vivir dento de un cierto horizonte de posibilidades (preferencias) e imposibilidades (rechazos) vitales, y entonces llamaré morada de la vida a ese "dentro"; o puede éste designar el modo como los hombres viven dentro de la morada de la vida, y entonces lo llamaré vividura. Según sean la "morada" y la "vividura" de la comunidad, así se habla, se piensa, se cree y se hace unas cosas con preferencia a otras.

El símil de la morada y la vividura servirá para precisar el pen- 
samiento que lo ha motivado. Todos los pueblos poseen una morada vital y a veces hay entre ellas aparentes analogías, e incluso un análogo mobiliario humano. En casi todo el mundo se encuentran hoy ferrocarriles, aeroplanos, templos, escuelas, bibliotecas, médicos, orquestas, gobernantes, cuerpo diplomático, ejército, etc. Piénsase entonces que el mundo de los hombres es uno, y que llegará a serlo del todo cuando los beneficios de la civilización se extiendan aún más. Obsérvese, no obstante, que mucho de lo visible en dicho "mobiliario" vital no deriva auténticamente de las posibilidades de la propia vividura. A veces los vehículos y los instrumentos técnicos son meras importaciones; o lo son los directores de las orquestas sinfónicas, o la música que ejecutan. Los ejemplos son demasiado obvios para que haga falta aumentarlos. Estrechando nuestra observación, se notará que incluso si en un pueblo se producen ciertas cosas análogas a las de otros sitios (filosofía, ciencias, máquinas, etc.), esas actividades no ocupan el mismo volumen dentro de la totalidad de la vida; no ocupan, sobre todo, el mismo lugar de importancia jerárquica. En unas moradas la actividad científica o industrial llena casi todo el espacio visible; en otras figuran como lujo infrecuente, o están relegadas a zonas de escasa estima -al sótano o a la bohardilla. Igual acontece a todo lo restante que integra el extenso ámbito de la vida: coraje bélico, moralidad política y social, sentido de la personalidad, distinción literaria y artística, fomento de la inteligencia, religiosidad espiritualizada o materializada ... De todo ello puede haber en un pueblo, aunque siempre dispuesto y ordenado según un sistema de capacidades y de preferencias. Lo cual significa que ahora nos importa primariamente no el qué y el cuánto de las actividades vitales, sino el peculiar modo de funcionar éstas. Las ideas, la llamada civilización, funcionarán aquí de un modo y allá de otro.

Uso en mis escritos, según conviene en cada momento, los términos "morada", "vividura", "estructura funcional", "disposición y manera de vida". Evito los términos "carácter" y "rasgos psicológicos", porque apuntan hacia algo ya fijamente dado, tipificado; o a algo parcial y perceptible sólo en sus resultados. Me interesa la vida histórica como movimiento, curso y dirección, como algo variable, conjugado con una "invariante" (me sirvo del término matemático) que haga captable lo que persista a lo largo de las mutaciones temporales. Persigo una constante vital, no lo lógicamente unívoco, un "modo" y no una sustancia. Las moradas de mi símil no están cerradas ni seclusas respecto de las de los vecinos. Los moradores salen y regresan; además del que se fabriquen, importan "mobiliario" de las más varias formas. Pero cuando se restablece la calma, y el morador se reintegra al dentro de su morada, aquél preferirá habitar en unas estancias más bien que en otras, por encontrarse más en su casa en unas 
que en otras, más a gusto en unas tareas que en otras. La libertad del morador dependerá de las posibilidades y de los límites de su mansión, sea como fuere lo traído a ella.

Como resultado de ser como es la vida histórica, las actividades y cualidades valiosas de un pueblo no siempre se incorporan auténticamente, y en el mismo modo, en la vida de otro. Los valores de cada "morada" arraigan únicamente en otras de parecida disposición, y, aun así, su función y sus resultados son muy diferentes. Descartes no ha funcionado en Alemania como en Francia, ni Hegel en Francia como en Alemania. Incluso observamos cómo dentro de un mismo país ciertos fenómenos valiosos quedan aislados o con escaso cultivo, cuando son excepcionales o inesperados respecto de los hábitos y preferencias dominantes: las ciencias en España, la filosofía en los Estados Unidos, la música en los pueblos anglosajones, tendencias místicas y pascalianas en Francia, la literatura heroica en Italia, etc. Por el contrario, cuando algo encaja de veras en la corriente de la propia vividura, los valores auténticamente queridos se multiplican y difunden con holgada espontaneidad y a gran altura: la ciencia natural y experimental ha florecido en Inglaterra desde el siglo XIII hasta hoy; el pensar teórico llenó nueve siglos de historia griega; la tensión épica del español se mantuvo. viva, en Fspaña o en sus dominios, desde el siglo $\mathrm{x}$ hasta el xvir. Así también en otros bien conocidos casos.

Un pueblo mantiene sus preferidas (y por tanto posibles) maneras de actividad valiosa, mientras le dura su ímpetu vital, o hasta que es modificado interiormente por otras gentes que vengan a mezclarse con él, o es aniquilado por algún cataclismo. Las invasiones germánicas acabaron por modificar la vividura del pueblo romano; los franconormandos cambiaron la estructura de los británicos; gentes del Norte de la Península ibérica, entrelazadas con la acción secular de moros y judíos, forjaron la especial disposición de vida de los españoles. Y ahí sigue estando. 